\title{
APROXIMAÇÃO DA REALIDADE DE VIDA E DE SAÚDE DA COMUNIDADE "RECANTO DA ALEGRIA”: DA SUA APREENSÃO À DEFINIÇÃO DE ESTRATÉGIAS DE INTERVENÇÃO
}

\author{
Vanessa Clarindo Rodrigues* \\ Maria Rita Bertolozzi** \\ Maria Cristina Marques***
}

RODRIGUES, V.C.; BERTOLOZZI, M.R.; MARQUES, M.C. Aproximação da realidade de vida e de saúde da comunidade "recanto da alegria": da sua apreensão à definição de estratégias de intervenção. Rev.latinoam.enfermagem, Ribeirão Preto, v. 6, n. 4, p. 83-93, outubro 1998.

O trabalho apresenta um processo desenvolvido junto a um projeto de investigação que busca identificar as condições de vida e saúde de uma comunidade, para propor estratégias de transformação à qualidade de vida dessa população. O local onde o estudo se desenvolveu pertence ao Distrito do Grajaú (SP). A totalidade das famílias que compunham a comunidade foi entrevistada através da aplicação de um questionário com perguntas abertas e fechadas, para compor um perfil em termos de características pessoais, de condições de vida e relativas ao processo saúde-doença. Os dados encontrados revelam um perfil que foi apresentado à comunidade no sentido de implementar alternativas conjuntas para a solução dos principais problemas/ questões por ela identificados.

UNITERMOS: diagnóstico de saúde, enfermagem em saúde coletiva

\section{INTRODUÇÃO}

O presente estudo descreve um processo que se desenvolveu junto a um projeto matriz que busca identificar as condições de vida e saúde de um grupo de pessoas que vivem em uma comunidade denominada "Recanto da Alegria", situada no Grajaú, distrito administrativo da região sul do Município de São Paulo. Esta investigação tinha por finalidade a proposição de estratégias que transformassem a qualidade de vida e de saúde dessa população, a partir do desenvolvimento de um processo participativo de intervenção na realidade.

Esse projeto foi realizado com a participação de alunos, monitores-bolsistas do curso de Enfermagem da Escola de Enfermagem (EE) da Universidade de São Paulo (USP), através do apoio da Coordenadoria de Assistência Social (COSEAS) da USP.

A proposta para o seu desenvolvimento emergiu a partir da própria experiência de vida das alunas, que fazem parte do mesmo grupo social que convive na localidade/objeto de estudo.

Dessa forma, Marques et al., movidos por uma série de inquietações decorrentes das condições de vida e de saúde da comunidade onde vivia, realizaram em 1993, uma caracterização histórico-ambiental da Administração Regional da Capela do Socorro, onde se localiza o Distrito de Grajaú para, a partir desses dados preliminares, propor um projeto de intervenção em saúde (MARQUES et al., 1993).

O processo para a construção dessa caracterização, ao lado dos conhecimentos adquiridos no curso de graduação em enfermagem, na EEUSP, promoveram um entendimento diferenciado sobre as questões de saúde, uma vez que se passou a compreender que o processo saúde-doença é determinado socialmente. Ou seja, a inserção social no sistema de produção determina diferentes padrões de desgaste e reprodução, que se traduzem em riscos e potencialidades distintos, os quais, por sua vez, se manifestam através de diferentes modos de adoecer e de morrer (LAURELL, 1983).

O desenvolvimento do processo de investigação conduziu ao entendimento de que o objeto do presente estudo não se situava no nível do indivíduo e sim do coletivo. Ora, este modo de abordar o estudo do processo saúde-doença requer a descrição/apreensão das condições de saúde de grupos, articuladas com as suas condições sociais. Isto permite visualizar a problemática de forma diferente daquela que ocorre quando se procede

\footnotetext{
* Graduanda do curso de Enfermagem da Escola de Enfremagem da Universidade de São Paulo

** Docente da Escola de Enfermagem da Universidade de São Paulo

*** Enfermeira
} 
a uma descrição biológica das condições de saúde, uma vez que não bastam os fatos biológicos, mas é necessário esclarecer como estes se articulam aos processos sociais, para que se proponha e se intervenha em função das reais demandas apresentadas pelo coletivo.

A enfermagem, como integrante do processo de produção em serviços de saúde, não pode se furtar à interpretação da realidade a partir dessa perspectiva, no sentido de efetivar intervenções que ajudem a modificar o perfil de condições de vida e de saúde da população.

Considerando o exposto, este trabalho tem por objetivos:

\section{OBJETIVOS}

- Identificar as condições de vida, trabalho e saúde do coletivo que conforma o "Recanto da Alegria".

- Verificar os principais problemas de saúde referidos por essa população.

- Identificar, junto a esse grupo, formas de encaminhamento para a solução das questões de saúde.

\section{METODOLOGIA}

\subsection{Cenário de estudo}

O local de estudo pertence à região de Capela do Socorro, que se situa no perímetro à maior área ecológica da cidade, localizada às margens das Represas Billings e Guarapiranga (MARQUES et al., 1993). Os Distritos que compõem essa Administração Regional são em sua maioria carentes em termos de equipamentos sociais, principalmente no que se refere à saúde.

O Recanto da Alegria foi a primeira favela urbanizada da cidade de São Paulo. Esse processo ocorreu em 1981, quando a Prefeitura do município de São Paulo financiou o material de edificação e apoiou a sua construção, que foi levada a cabo pelos próprios moradores, organizados sob a forma de mutirão.

No momento em que foi realizado o estudo, viviam no local cerca de 50 famílias, que apresentavam, a grosso modo, todas as repercussões de uma dada forma de inserção social. Assim, o nível de desemprego era alto, os salários baixos, grande número de mães trabalhavam e deixavam seus filhos em creche ou sozinhos no interior dos domicílios, além de se encontrar chefes de família que, embora empregados, não conseguiam prover as necessidades familiares, entregando-se ao uso constante de bebidas alcoólicas.

Com a urbanização, mudaram as condições ambientais do Recanto, mas alguns problemas ainda permaneciam, como as fossas constantemente sobrecarregadas, esgoto a céu aberto em direção ao pequeno córrego próximo, tubulações sanitárias vez e outra entupidas, bem como presença de lixo e ratos nos terrenos baldios o que, sistematicamente, colocava em risco a população da localidade.

\subsection{População}

Todas as famílias que compunham o Recanto da Alegria na época da realização do estudo, que totalizaram um número de 48 .

\subsection{Variáveis selecionadas para o estudo}

As variáveis do estudo se referem às condições de vida, trabalho e ao processo saúde-doença. Nesse sentido, foram discriminadas:

- características gerais sobre as famílias (sexo, idade, procedência, chefia de família, renda per capita, escolaridade, religião).

- condições de trabalho (inserção no mercado de trabalho, registro em carteira).

- condições de vida (propriedade da moradia, número de moradores, número de cômodos e outros indicadores de qualidade de vida).

- características relativas ao processo saúde-doença (hábito de fumar, consumo de álcool, reprodução biológica, principais causas de morte, morbidade referida, esquema de vacinação, serviços de saúde utilizados, criação de animais no domicílio, referências sobre principais problemas de saúde/alternativas de resolução para os mesmos).

Essas variáveis conformaram um instrumento com perguntas abertas e fechadas que foi submetido a pré-teste para validação.

\subsection{Coleta de dados}

Os dados foram coletados durante os meses de junho a agosto de 1995, através de visitas domiciliárias realizadas pelas próprias pesquisadoras.

As entrevistas duraram em média 30 minutos.

\subsection{Tratamento dos resultados}

Todas as informações obtidas foram processadas em arquivo único de dados e foi feita análise estatística utilizando-se a formatação gráfica do software EpiInfo95.

O conteúdo referente às perguntas abertas foi sistematizado para, posteriormente, ser verificada a freqüência com que cada um dos temas/opiniões apareceu.

No momento seguinte, os resultados foram 
apresentados a uma parcela da população do Recanto da Alegria, na tentativa de buscar, em conjunto, formas de encaminhamento para a solução dos principais problemas.

\section{RESULTADOS E DISCUSSÃO}

\subsection{Perfil de caracterização geral das famílias}

Como já foi mencionado, a população do Recanto da Alegria, na época em que a coleta de dados foi realizada, era composta por 48 famílias, com um total de 233 indivíduos, sendo que destes, $48,5 \%$ eram mulheres e 51,5\% eram homens, não diferindo muito do perfil que se revela no município de São Paulo, o qual segundo dados da Fundação Sistema Estadual de Análise de Dados (SEADE), apontava um total de $51,8 \%$ de mulheres e 48,2\% de homens em 1993 (FUNDAÇÃO SISTEMA ESTADUAL DE ANÁLISE DE DADOS. SEADE, 1994).

No que se refere ao presente estudo, cerca de $35 \%$ das pessoas se encontravam na faixa etária entre 0 a 14 anos, sendo que $3 \%$ pertenciam ao grupo de menores de 1 ano e $6 \%$ de 1 a 4 anos. Entre 15 a 44 anos estava concentrada $52 \%$ da população, o que corresponde à faixa etária economicamente produtiva (Figura 1). Segundo dados do Anuário Estatístico do Brasil em 1991, 34,7\% da população brasileira tinha entre 0 a 14 anos e na idade entre 15 a 44 anos encontrava-se cerca de $47,2 \%$, dados semelhantes aos encontrados no Recanto da Alegria. Conforme indicam as informações, verifica-se o predomínio de uma população eminentemente jovem, típica de países em desenvolvimento (FUNDAÇÃO INSTITUTO BRASILEIRO DE GEOGRAFIA E ESTATÍSTICA. IBGE, 1993).
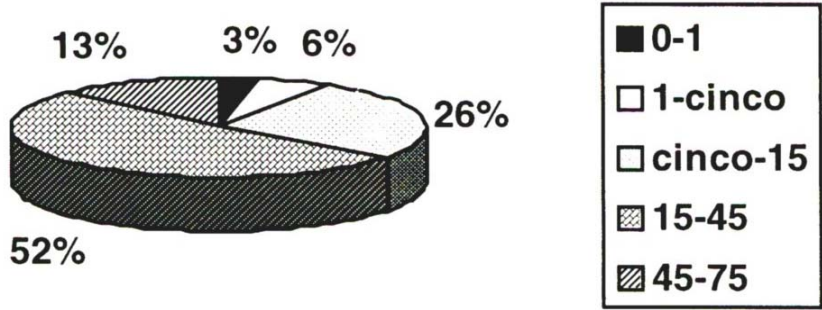

Figura 1 - Distribuição da população por idade. São Paulo, 1995

No que se refere à procedência dos moradores, a maioria $(57,1 \%)$ era proveniente do próprio Estado de São Paulo, enquanto os demais haviam migrado da Bahia, Ceará, Minas Gerais e Pernambuco principalmente, conforme pode ser visto através da Tabela 1 . Dos moradores procedentes de São Paulo, 85,7\% estavam concentrados na faixa etária entre 0 a 21 anos, sendo portanto, autóctones do Recanto da Alegria, evidenciando que não haviam passado por processos migratórios, uma vez que o Recanto da Alegria foi criado em 1974. Já as pessoas das faixas etárias com maior idade, eram procedentes de outros Estados (Figura 2), evidenciando provavelmente o resultado do grande fluxo migratório que a região Sudeste recebeu na década de 70 . A intensa migração de nordestinos justifica-se pela histórica estagnação econômica do Nordeste, o que levaria a população a buscar novas estratégias de sobrevivência, além da atração exercida pelo processo de industrialização acelerado na região Sudeste durante aquela época (PRATA, 1994).

No que se refere ao tempo de moradia dos chefes das famílias em São Paulo, verificou-se que a maioria se encontrava no município de São Paulo há pelo menos 20 $\operatorname{anos}(54,2 \%)$.

Tabela 1 - Distribuição dos moradores do recanto da alegria segundo unidade federada de procedência. São Paulo, 1995

\begin{tabular}{ccc}
\hline $\begin{array}{c}\text { UNIDADE FEDERADA } \\
\text { DE PROCEDÊNCIA }\end{array}$ & $\mathbf{N}^{\mathbf{p}}$ & $\mathbf{\%}$ \\
\hline São Paulo & 133 & 57,1 \\
Bahia & 54 & 23,2 \\
Ceará & 18 & 7,7 \\
Minas Gerais & 16 & 6,9 \\
Pernambuco & 5 & 2,1 \\
Maranhão & 3 & 1,3 \\
Rio de Janeiro & 2 & 0,9 \\
Paraná & 1 & 0,4 \\
Santa Catarina & 1 & 0,4 \\
\hline TOTAL & $\mathbf{2 3 3}$ & $\mathbf{1 0 0}$ \\
\hline
\end{tabular}

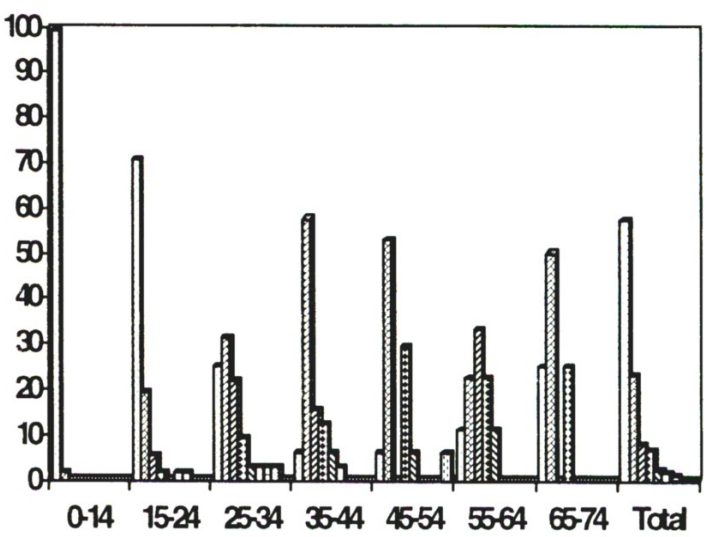

\begin{tabular}{|c|c|c|c|c|}
\hline C SáoPalo & OBahia & vacerá & ⿴囗M Cerais & \& Pernantuoo \\
\hline QMerahẽo & QR teneiro & QPará & ES Catarina & \\
\hline
\end{tabular}

Figura 2 - Distribuição dos moradores do recanto da alegria segundo faixa etária e unidade federada de procedência. São Paulo, 1995 
Ressalta-se que 79,2\% das famílias tinham como chefe a figura do sexo masculino, enquanto $20,8 \%$ eram do sexo feminino. Cabe destacar que a condição chefe de família foi definida pelos próprios entrevistados. Além disso, verificou-se o fato de que os mais novos chefes de família do sexo masculino tinham a idade de 22 anos e as mais novas chefes de família do sexo feminino tinham 38 anos de idade. Segundo o Anuário Estatístico do Brasil (IBGE, 1994) os homens ainda predominam como chefes de família $(79,7 \%)$ em relação às mulheres $(20,3 \%)$. Entretanto, de 1983 a 1993, esse índice aumentou de 17\% para 22\% para o sexo feminino (MERCADO, 1996), o que sugere uma maior inserção da mulher no mercado de trabalho. Esse fenômeno pode ser explicado pela crescente deterioração das condições de trabalho/renda (IBGE, 1992), o que tem determinado a necessidade de introdução da mão de obra feminina no mercado de trabalho, sendo que cada vez mais, nos tempos atuais, esse gênero é um dos protagonistas no sistema de produção. A própria Organização Mundial da Saúde reconhece esse fato ao informar que as mulheres estão atuando em outros campos que não o tradicional acompanhamento do crescimento das crianças e a produção de alimentação para a sobrevivência (WHO, 1995). Vale a pena destacar o fato de que a situação da mulher chefe de família nas classes sociais de menor poder de consumo no Brasil é menos privilegiada que a do chefe de família do sexo masculino. Em 1980, 61\% das famílias chefiadas por mulheres tinham um rendimento médio mensal não superior a 1 salário mínimo (DADOS, 1986-b). Segundo dados da "Folha de São Paulo" (MERCADO, 1996), em 1993, as mulheres ainda recebiam menos que os homens, sendo que, para cada $\mathrm{R} \$ 100,00$ recebidos pelos homens, a mulher recebe cerca da metade, ou seja, $\mathrm{R} \$ 50,60$.

No que se refere à renda das famílias do Recanto da Alegria, verificou-se que era de até 15 salários mínimos, sendo que 2,1\% das famílias recebiam até 1 salário mínimo (apenas 1 família com 3 pessoas sobrevivia com essa renda), $39,6 \%$ entre 2 a 4 salários $(31,6 \%$ famílias com 4 pessoas; $21 \%$ com 6 pessoas; $15,8 \%$ com 5 pessoas; $10,5 \%$ com 2 e 3 pessoas cada e 5,3\% entre 9 e 10 pessoas cada); $50 \%$ entre 5 a 9 salários mínimos (famílias com 3 (25\%), 4, 5, 6 (16,7\%) respectivamente, $8,9(8,3 \%)$ respectivamente, 1 e 2 pessoas $(4,2 \%)$ respectivamente) e entre 10 a 15 salários mínimos $(8,3 \%)$ com famílias compostas por $4,5,6$ e até $8(25 \%)$ pessoas (Tabela 2).
Tabela 2 - Distribuição das famílias segundo renda per capita em salários mínimos, São Paulo, 1995

\begin{tabular}{ccc}
\hline $\begin{array}{c}\text { RENDA PER CAPITA EM } \\
\text { SALARIOS MIINIMOS }\end{array}$ & $\mathbf{N}^{\mathbf{w}}$ & \% \\
\hline 0 a 0,4 & 5 & 10,4 \\
0,5 a 0,9 & 17 & 35,4 \\
1,0 a 1,4 & 11 & 22,9 \\
1,5 a 1,9 & 6 & 12,5 \\
2,0 a 2,4 & 3 & 6,3 \\
2,5 a 2,9 & 4 & 8,3 \\
3,0 ou mais & 2 & 4,2 \\
\hline TOTAL & $\mathbf{4 8}$ & $\mathbf{1 0 0}$ \\
\hline
\end{tabular}

Segundo a literatura, $54 \%$ da população do município de São Paulo recebe mais de 5 salários mínimos. No Recanto da Alegria observou-se que 58,3\% da população ganhava entre 5 e 15 salários mínimos. Cabe registrar que a região metropolitana de São Paulo concentra $27 \%$ dos trabalhadores que ganham entre 5 a 10 salários mínimos (KON, 1994). BRANT (1989) afirma que para sobreviver ou completar a renda, a população brasileira tem feito uso de algumas estratégias, tais como o aumento da jornada de trabalho através de horas extras, a incorporação de outros membros da família no sistema de produção, a utilização de processos de produção doméstica, como a venda de produtos próximos à vizinhança, ou mesmo introduzindo crianças e adolescentes precocemente no trabalho. Através dessas alternativas, as mulheres dobram ou até triplicam a jornada de trabalho, combinando serviço autônomo com serviço assalariado. Cabe ressaltar que, em virtude disso, também os aposentados continuam trabalhando, na perspectiva de aumentar a renda recebida que não é suficientemente provida pela seguridade social.

Com relação à escolaridade, $5 \%$ das crianças entre 7 e 9 anos não estavam na escola. No que toca à população total, $12 \%$ eram analfabetos; $3,9 \%$ tinham o $1^{\circ}$ grau completo; $1,5 \%$ tinham o $2^{\circ}$ grau completo e $0,5 \%$ tinham o grau superior completo. Dos que tinham o $1^{\circ}$ grau completo, $25 \%$ tinham entre 15 e 19 anos e $75 \%$ tinham entre 20 e 29 anos. Os analfabetos se encontravam distribuídos nas diferentes faixas etárias. Pode-se dizer que o estudo reproduz o quadro nacional, no qual subsistem diversas fontes de desigualdades quanto ao acesso e à permanência no sistema escolar, sendo possível atribuir essa situação ao nível sócio-econômico da família, lugar e região da residência, condição étnica, necessidade de trabalho precoce, bem como ideologia adotada pelo país, em relação à essa questão, dentre outros (IBGE, 1992). Cabe enfatizar ainda que a maior parte da população adulta: $85 \%$ (entre 20 e 74 anos) não tinha o $1^{\circ}$ grau completo ou era de analfabetos (Tabela 3 ). 


\begin{tabular}{|c|c|c|c|c|c|c|c|c|c|c|}
\hline \multirow[b]{2}{*}{ GRAU DE INSTRUÇÃO } & \multirow[b]{2}{*}{$7-9$} & \multirow[b]{2}{*}{$10-14$} & \multirow[b]{2}{*}{$15-19$} & \multicolumn{3}{|c|}{ IDADE } & \multirow[b]{2}{*}{$40-49$} & \multirow[b]{2}{*}{$50-59$} & \multirow[b]{2}{*}{$\geq 60$} & \multirow[b]{2}{*}{ Total } \\
\hline & & & & $20-24$ & $25-29$ & $30-39$ & & & & \\
\hline Não está na & 1 & - & - & - & - & - & - & - & - & 1 \\
\hline escola & 5,0 & - & - & - & - & - & - & - & - & 0,5 \\
\hline $1^{\circ} \mathrm{G}$ & - & - & 2 & 4 & 2 & - & - & - & - & 8 \\
\hline completo & - & - & 6,3 & 15,4 & 12,5 & - & - & - & - & 3,9 \\
\hline $1^{\circ} \mathrm{G}$ & 19 & 34 & 21 & 14 & 10 & 24 & 21 & 8 & 1 & 152 \\
\hline incompleto & 95,0 & 100 & 65,6 & 53,8 & 62,5 & 82,8 & 72,4 & 61,5 & 12,5 & 73,4 \\
\hline $2^{\circ} \mathrm{G}$ & - & - & - & 2 & 1 & - & - & - & - & 3 \\
\hline completo & - & - & - & 7,7 & 6,3 & - & - & - & - & 1,5 \\
\hline $2^{\circ} \mathrm{G}$ & - & - & 9 & 4 & 2 & 1 & 1 & - & - & 17 \\
\hline incompleto & - & - & 28,1 & 15,4 & 12,5 & 3,4 & 3,4 & - & - & 8,2 \\
\hline superior & - & - & - & - & 1 & - & - & - & - & 1 \\
\hline completo & - & - & - & - & 6,3 & - & - & - & & 0,5 \\
\hline \multirow[t]{2}{*}{ analfabeto } & - & - & - & 2 & - & 4 & 7 & 5 & 7 & 25 \\
\hline & - & - & - & 7,7 & - & 13,8 & 24,1 & 38,5 & 87,5 & 12 \\
\hline \multirow[t]{2}{*}{ TOTAL } & 20 & 34 & 32 & 26 & 16 & 29 & 29 & 13 & 8 & 207 \\
\hline & 9,7 & 16,4 & 15,5 & 12,6 & 7,7 & 14 & 14 & 6,2 & 3,9 & \\
\hline
\end{tabular}

É importante ressaltar que as pessoas que não tinham o $1^{\circ}$ grau completo compunham grande parte do grupo de chefes de família (Tabela 4). Evidencia-se ainda uma grande porcentagem de jovens que não estudavam: uns porque trabalhavam e não conciliavam horário, outros por não se adaptarem à escola, além de outros, que na perspectiva do auxílio domiciliar, ajudavam no cuidado dos irmãos enquanto os pais trabalhavam.

Tabela 4 - Distribuição dos chefes das famílias do recanto da alegria segundo grau de escolaridade. São Paulo, 1995

\begin{tabular}{ccc}
\hline GRAU DE ESCOLARDADE & $\mathbf{N}^{\mathbf{w}}$ & $\mathbf{0}$ \\
\hline $1^{\circ}$ grau incompleto & 30 & 62,5 \\
$1^{\circ}$ grau completo & 3 & 6,3 \\
$2^{\circ}$ grau incompleto & 2 & 4,1 \\
analfabeto & 13 & 27,1 \\
\hline TOTAL & $\mathbf{4 8}$ & $\mathbf{1 0 0}$
\end{tabular}

Ainda na tentativa de caracterizar as famílias em relação a algumas questões de natureza pessoal, os entrevistados foram também indagados sobre o tipo de religião predominante. Neste sentido, a religião católica foi a que prevaleceu $(95,8 \%)$, sendo citada ainda a religião cristã $(2,1 \%)$ e uma pessoa que referiu não ter religião $(2,1 \%)$.

\subsection{Perfil relativo às condições de trabalho}

Em relação às condições de trabalho verificou- se que cerca de $29,2 \%$ das famílias tinham pelo menos uma pessoa que trabalhava, sendo que foram encontrados domicílios nos quais até 5 pessoas trabalhavam: em 2,1\% dos casos. Entretanto, a maioria (47,9\%) tinha até 2 pessoas trabalhando (Tabela 5).

Tabela 5 - Distribuição das famílias segundo número de pessoas que trabalhavam. São Paulo, 1995

\begin{tabular}{ccc}
\hline $\begin{array}{c}\text { NÚMERO DE PESSOAS } \\
\text { QUE TRABALHAM POR } \\
\text { FAMÍLIA }\end{array}$ & N DE FAMÍLIAS & \% \\
\hline 01 & 14 & 29,2 \\
02 & 23 & 47,9 \\
03 & 07 & 14,5 \\
04 & 03 & 6,3 \\
05 & 01 & 2,1 \\
\hline TOTAL & $\mathbf{4 8}$ & $\mathbf{1 0 0}$ \\
\hline
\end{tabular}

Dos 147 indivíduos acima dos 15 anos de idade, $67,4 \%$ estavam trabalhando no momento em que foi realizada a investigação. Cabe ressaltar que não se encontrou nenhuma pessoa menor que 15 anos de idade inserida no sistema de produção.

Daqueles que estavam trabalhando, encontrouse aproximadamente $33,5 \%$ que se alocavam no setor de prestação de serviços (serventia, segurança); $31,4 \%$ no setor de indústria e transporte; $16 \%$ no comércio; $10 \%$ no setor administrativo e burocrático; $6,1 \%$ no setor agropecuário; $2 \%$ no setor técnico, científico e artístico e 
$1 \%$ que trabalhavam na organização da própria comunidade. Dos que não trabalhavam fora $(32,6 \%)$, $39,6 \%$ eram donas de casa, $12,5 \%$ aposentados e $47,9 \%$ estavam desempregados.

No que se refere à inserção no modo de produção, cerca de $58,2 \%$ possuíam registro em carteira, 39,8\% não possuíam registro e $2 \%$ referiram ser autônomos.

Os que possuíam ocupação com registro em carteira, predominantemente tinham idade entre 16 e 24 anos (42\%), seguidos da idade de 25 a 34 anos (24,6\%), 35 a $44 \operatorname{anos}(22,8 \%), 45$ a $54 \operatorname{anos}(8,8 \%)$ e 55 a 64 anos $(1,8 \%)$.

Os que não possuíam registro em carteira encontravam-se na faixa etária de 35 a 44 anos (41\%), 16 a 24 anos (23,1\%), 25 a 34 anos (17,9\%), 45 a 54 anos $(10,3 \%), 55$ a 64 anos (5,1\%), 65 a 74 anos (2,6\%). Já os autônomos se encontravam na faixa etária entre os 25 aos $34 \operatorname{anos}(50 \%)$ e dos 45 aos 54 anos (50\%).

É importante verificar que os trabalhadores que tinham registro em carteira eram predominantemente jovens. Ao se avaliar essa condição, segundo a faixa etária, verifica-se que a progressão na idade significou, para o grupo em estudo, diminuição da posse de registro em carteira. $\mathrm{O}$ avançar na idade pode significar que as pessoas passam a trabalhar sem registro e sem qualquer benefício, o que é digno de nota, pois são pessoas que, legalmente, estariam mais próximas de receber o benefício da aposentadoria, caso estivessem formalmente inseridas no mercado de trabalho.

\subsection{Perfil relativo às condições de vida}

Em relação à propriedade da moradia, encontrouse que $79,2 \%$ dos domicílios eram próprios, $16,6 \%$ cedidos e $4,2 \%$ alugados. Na maioria dos domicílios havia 4 moradores $(22,9 \%)$ e a maioria das casas possuía 2 cômodos $(35,4 \%)$, verificando-se que somente em um caso havia uma pessoa no domicílio. Ora, o número de cômodos por moradia pode ser um indicador de acesso aos bens de consumo, uma vez que o valor financiado pela Prefeitura aos moradores do Recanto da Alegria, havia sido o mesmo para todos e permitia a construção de habitações com até 2 cômodos, excetuando-se o banheiro. Aqueles que puderam contar com recursos próprios, conseguiram expandir suas casas construindo um número maior de cômodos.

A moradia é um elemento denunciador das diversas formas de segregação sócio-espacial. Segundo PAVIANI (1994), as grandes cidades são ocupadas por setores de moradia de baixa qualidade construtiva, muitas vezes erguidas através de barganhas políticas entre os processos eleitorais.

Na época da urbanização do Recanto da Alegria, em meados de 1981, a população era composta por 36 famílias cadastradas pela Prefeitura. Observa-se, portanto, um aumento de $33,3 \%$ do número de famílias, crescimento que pode ser explicado pela necessidade de fixação no local, devido às condições sócio-econômicas, fato que determinaria a compartilha da moradia com os pais, mesmo após a constituição de novas famílias. Outro fato que explica esse aumento é a chegada de membros familiares de outras cidades ou bairros de São Paulo que, também por questões sócio-econômicas, foram obrigados a se instalar naquele local. A forma mais comum para acomodar essas novas famílias foi através da construção de novos cômodos sobre as casas já existentes, uma vez que o espaço físico para a construção horizontal praticamente inexistia.

$\mathrm{Na}$ época da urbanização daquela comunidade, todas as casas eram próprias, e foram construídas através de mutirão e em local determinado/designado pela Prefeitura. Conforme colocado anteriormente, o que ocorre hoje é que as novas famílias se instalaram nas casas dos pais ou parentes construindo novos cômodos, sendo que alguns nada pagavam por isso e outros passaram a pagar aluguel, ainda que tendo algum grau de parentesco com o dono da casa.

Há ainda que lembrar que as análises de padrão de vida que levam em conta somente o tipo de edificação podem simplificar ou mesmo encobrir a real situação que envolve as condições de sobrevivência. Assim, é necessário que se considere também o tamanho das moradias, o número e as características dos cômodos, a adequação entre o espaço disponível às atividades familiares ali exercidas, bem como a estabilidade dos mesmos de acordo com a apropriação do imóvel - próprio, alugado, cedido, invadido - entre outras situações (TROYANO et al., 1991).

Ainda na perspectiva de aumentar a percepção sobre a qualidade de vida daquela comunidade, foram coletados dados sobre iluminação, ventilação e umidade, segundo a opinião dos moradores e do observador (entrevistador). De acordo com os entrevistados, a iluminação foi considerada boa (70,8\%), regular (20,8\%) e ruim (8,4\%). Para o observador, os resultados foram semelhantes: boa $(52,1 \%)$, regular $(35,4 \%)$ e ruim $(12,5 \%)$. No que se refere à umidade, foi relatada pelos entrevistados em $16,7 \%$ dos casos como sempre presente; às vezes $(56,3 \%)$ e não havia $(27 \%)$; enquanto que, para o observador: sempre existente (22,9\%), às vezes $(52,1 \%)$ e não havia $(25 \%)$. No que se refere à ventilação obteve-se para o entrevistado, $50 \%$ de respostas considerando-a boa, 41,7\% regular e 8,3\% não havia, enquanto que para o observador obteve-se $64,6 \%$ boa, 31,2\% regular e 4,2\% não havia.

Outra questão relacionada às condições financeiras para a construção da moradia é o fato de que algumas famílias não conseguiram proceder ao 
acabamento do domicílio. Como resultado disso, podiam ser encontradas com freqüência: infiltração, umidade, falta de iluminação e ventilação, que sem dúvida, podem refletir sobre as condições de saúde dos moradores, ainda que conforme visto anteriormente, para a maioria deles, os problemas de iluminação e umidade foram menos percebidos pelos próprios do que para o observador/ entrevistador.

$\mathrm{O}$ abastecimento de água era feito pela rede pública em $100 \%$ dos casos, sendo que em $54,2 \%$ dos domicílios a água utilizada não recebia nenhum tratamento, em $41,6 \%$ das situações era filtrada e em $4,2 \%$ era fervida.

SEMECHINI \& ARAÚJO (1989), ao realizarem estudo sobre essa questão na metrópole de São Paulo e interior, mostraram que os serviços de abastecimento de água não atendem à demanda do poder público no sentido de acompanhar o crescimento do número absoluto de domicílios. O estudo feito por KOWARICK et al. (1990) revela que os centros urbanos, especialmente São Paulo, apresentam níveis de cobertura próximos a $100 \%$, mas a medida em que nos distanciamos do centro e nos dirigimos à periferia esta porcentagem diminui. Sob a visão de DUCHIADE (1995), a maioria dos municípios $(95,6 \%)$ já dispõem de rede de distribuição de água, embora em boa parcela desses municípios a distribuição se restrinja ao suficiente para evitar a sede.

Ainda que o PLANASA, plano de políticas públicas predominantemente centrado na expansão da rede de água nas décadas de 70 e 80 , possibilitou a ampliação do número de domicílios com fornecimento de água pela rede pública (Vetter apud COSTA, 1990; BRANT, 1989) de $54,4 \%$ para $76 \%$, esse aumento de cobertura domiciliar foi extremamente discriminatório ao se considerarem os critérios regionais, demográficos e sociais.

Voltando ao presente estudo e referindo-se às condições ambientais, verificou-se que a maioria do lixo era coletado pela rede pública $(93,8 \%)$, sendo que $2 \%$ das famílias relataram que era queimado, enquanto $4,2 \%$ referiram que era jogado em terreno baldio e/ou próximo ao córrego, o que via de regra provocava odor e perigo de contaminação. De um modo geral, segundo o IBGE (1993) em 1991, 69,9\% dos domicílios do país eram atendidos pela coleta de lixo, sendo que esta porcentagem aumenta quando se focaliza a região Sudeste $(82 \%)$. TROYANO (1991) confirma que a coleta de lixo regular tem servido à aproximadamente $97,1 \%$ das famílias da região metropolitana de São Paulo. Destas, 2,9\% não tem o lixo coletado regularmente e pouco mais da metade $(52,5 \%)$ tem o hábito de jogá-lo em terreno baldio. Por outro lado, dados do SEADE (1992) revelam a existência de outras práticas como a queima, o aterro do lixo e a exposição do mesmo a céu aberto, corroborando os dados encontrados neste estudo.

\subsection{Perfil de características relativas ao processo saúde-doença}

No que se refere ao perfil de características do processo saúde-doença, verificou-se que a maioria das pessoas a partir de 15 anos de idade $(79,8 \%)$ referiu não fumar. Dos que fumavam $(20,2 \%)$, a maioria se encontrava na faixa etária dos 15 aos 54 anos e referiu fazer uso de cigarro, cachimbo ou cigarro de palha. Ora, o risco que traz o hábito de fumar vem ganhando importância no perfil epidemiológico das sociedades. Segundo a Organização Mundial da Saúde (OMS), estima-se que durante os anos 90, 3 milhões de pessoas podem vir a morrer ao ano por causas atribuíveis ao cigarro (WHO, 1995).

Ainda com referência à população com 15 anos e mais, a maioria referiu não ingerir bebida alcoólica $(76 \%)$. Daqueles que referiram beber, $58,9 \%$ encontravam-se na faixa etária entre 15 a 34 anos de idade, $35,7 \%$ dos 35 aos 54 anos e 5,4\% dos 55 aos 74 anos. A maioria referiu fazer uso de bebida alcoólica socialmente $(83,9 \%)$, mas encontraram-se também aqueles que referiram beber diariamente $(3,6 \%)$, até aqueles que bebiam a ponto de se embriagar (12,5\%).

Com a finalidade de obter alguns dados a respeito da reprodução biológica, indagou-se também a respeito do aborto. A porcentagem de casos referidos foi de $33,4 \%$ (16 famílias), sendo que $56,3 \%$ das pessoas referiram apenas um caso; $37,2 \%$, dois casos; e $6,5 \%$, três casos. Relatou-se ainda a ocorrência de 1 natimorto.

As mortes referidas em crianças menores de 1 ano foram relatadas por $16,6 \%$ das famílias, sendo causadas por pneumonias $(22,2 \%)$, prematuridade $(22,2 \%)$, desidratação $(11,1 \%)$, gastroenterocolite aguda $(11,1 \%)$, septicemia $(11,1 \%)$. Ainda encontrou-se cerca de $22,2 \%$ das pessoas que relataram desconhecimento da causa de morte. Ao se considerar o grupo de crianças de 1 a 5 anos de idade, $0,6 \%$ das famílias referiram ter ocorrido óbito nessa faixa etária, devido a doenças respiratórias $(33,3 \%)$ e doenças infecciosas $(66,7 \%)$.

Segundo dados da literatura, ocorrem cerca de 2 milhões de episódios de infecções respiratórias agudas (IRA)/ano com 4,1 milhões de morte/ano. Essas infecções são a primeira causa de morte em crianças em países em desenvolvimento. As pneumonias são responsáveis por mais de $80 \%$ das mortes por infecções agudas nas Américas (WHO, 1995).

As causas acima relatadas reproduzem o padrão de mortalidade no país na faixa etária correspondente. As condições de vida, bem como o acesso à assistência à saúde têm se constituído nos pilares do padrão epidemiológico evidenciado.

No final da década de 80 no Estado de São Paulo, a mortalidade infantil era inferior a 30 por mil, mas ainda 
atinge valores superiores a 100 por mil em algumas regiões do Nordeste (LAURENTI, 1990).

Cabe salientar que em São Paulo, a partir da metade da década de 70 , tem havido uma redução acentuada na mortalidade infantil. Segundo ORTIZ (1982) isso se deve à aplicação de medidas sanitárias no período, como por exemplo, expansão da rede de água e maior acesso da população aos serviços de assistência médica, entre outros.

No que se refere à cobertura vacinal, todas as famílias referiram que as crianças tinham esquema de vacinação completo. Nos países em desenvolvimento mais de um milhão de mortes anuais por sarampo, tétano neonatal e coqueluche têm sido prevenidas através de programas de imunização. As doenças preveníveis por vacinação estão em geral em declínio no mundo, graças à expansão do Programa Ampliado de Imunizações. No entanto, considera-se que ainda há cerca de 2,9 milhões de mortes/ano que poderiam ser evitadas através da adoção de esquemas completos de vacinação (DADOSb, 1989).

Quando perguntados a respeito da presença de algum problema de saúde nos familiares, no momento em que se realizava a entrevista, houve resposta afirmativa de $58,3 \%$ em relação a todos os grupos de idade, sendo que $62,8 \%$ das respostas se referiram às mulheres e $37,2 \%$ em homens. Prevaleceram respostas relativas às doenças cardio-vasculares $(28,2 \%)$, respiratórias $(21,7 \%)$, gastrointestinais (13\%), ósteo-articulares $(8,6 \%)$, mentais $(6,5 \%)$, neurológicas $(4,3 \%)$, crônico-degenerativas $(4,3 \%)$, dermatológicas $(4,3 \%)$, dentre outras.

Já quando indagados à respeito de morte em adultos, obteve-se $20,8 \%$ de resposta afirmativa, sendo que $25 \%$ dos óbitos se referiram a pessoas que pertenciam à família nucleada e $75 \%$ a agregados que residiam no domicílio. As causas de morte alocaram-se principalmente no grupo das cardio-vasculares, gastrointestinais, respiratórias, infecciosas, além de outras que apresentaram menor expressividade.

Das 50 milhões de mortes que ocorrem a cada ano, quase $4 / 5$ estão concentradas em países em desenvolvimento e quase metade está diretamente relacionada a doenças infecciosas ou parasitárias (WHO, 1995).

As doenças não transmissíveis e as crônicodegenerativas são responsáveis por cerca de $40 \%$ das mortes em países em desenvolvimento e $75 \%$ em países industrializados. As doenças cardiovasculares câncer e diabetes mellitus matam cerca de 25 milhões de pessoas ao ano, sendo que $2 / 3$ estão concentradas em países em desenvolvimento. As doenças cardiovasculares causam 12 milhões de mortes no mundo/ano, sendo responsáveis por metade das mortes em muitos países desenvolvidos e constituem também uma das principais causas de morte em muitos países em desenvolvimento - a maior causa em adultos. Há que se verificar que muitos eventos cardiovasculares não são fatais, mas suficientemente debilitantes para afetar seriamente a habilidade funcional dos acometidos (WHO, 1995).

Nos países em desenvolvimento que se encontram no primeiro estágio ou na metade da transição epidemiológica, cerca de um terço das mortes ocorre abaixo dos 5 anos, sendo que outra parcela se concentra entre os 5 a 64 anos e 1/3 acima dos 65 anos, sendo as principais causas as doenças transmissíveis e parasitárias (WHO, 1995).

No estágio final da transição epidemiológica, as doenças transmissíveis em crianças estão em geral controladas e a vasta maioria das mortes ocorre tardiamente (quase 3/4 ocorrem após 65 anos), como resultado de doenças crônicas (WHO, 1995).

O que se tem verificado no nosso país é a diminuição das doenças infecciosas e parasitárias como causa de óbito em ambos os sexos e um aumento das taxas correspondentes aos neoplasmas e crônicodegenerativas de um modo geral. No Rio de Janeiro, entre 1970 e 1980, a mortalidade masculina sofreu um aumento de $45 \%$ em relação às causas externas, enquanto houve um decréscimo de $29 \%$ nas complicações da gravidez, parto e puerpério, interferindo na mortalidade materna. Essas taxas de maneira geral também tem sido evidenciadas em São Paulo (DADOS-a, 1986).

LAURENTI (1990), ao comentar o fenômeno da transição epidemiológica e referindo-se a documento apresentado em reunião de centros colaboradores da OMS para a classificação de doenças em 1990, chama a atenção para a combinação contraditória entre o declínio da mortalidade e o aumento da morbidade. Assim, em termos de indicadores, as doenças sofrem mudanças: da predominância das doenças infecciosas passam a ocupar a vanguarda, as crônico-degenerativas e, por outro lado, as causas externas e agudas, quase sempre de alta letalidade, passam para patologias de longa duração, o que gera um acúmulo de doenças na população, principalmente na população mais idosa.

Em relação ao tipo de serviços de saúde utilizados pelas famílias do presente estudo, verificou-se que 70,8\% da população recorriam à assistência médica da rede pública e 29,2\% tinham convênio.

Quando da presença de algum problema de saúde, $35,4 \%$ referiram utilizar medicação caseira, 31,3\% relataram ir ao médico, 20,8\% disseram que se automedicavam, 10,4\% procuravam a farmácia e 2,1\% informaram nada fazer. Entre as medicações caseiras citadas destacaram-se chás $(83 \%)$, xaropes $(7,5 \%)$, "preparados" (5\%), "banhos" $(2,3 \%)$ e soro caseiro $(2,2 \%)$.

Cerca de $52,1 \%$ da população referiram criar 
animais em casa, como gato, cachorro, aves e coelhos e, aproximadamente $70,8 \%$ dos entrevistados afirmaram a presença de insetos, baratas e ratos nos domicílios.

Os entrevistados foram também indagados se havia algum tipo de problema que os preocupava e, em decorrência disso(56,3\%), referiram que haviam problemas relativos ao domicílio ou próximo a ele (26\%), relativos ao processo saúde-doença $(20 \%)$, à sobrevivência $(15,1 \%)$, ao bem-estar $(14,7 \%)$, à organização da comunidade $(6,8 \%)$, à questões educativas $(7,4 \%)$, à segurança $(5 \%)$ e ao relacionamento familiar (5\%). Segundo os entrevistados, em 54,2\% das opiniões não havia solução para os problemas levantados.

Os que referiram haver solução $(45,8 \%)$, imputavam a responsabilidade sobre esses problemas à outros, como "vizinhos" (42,8\%), "Prefeitura" $(35,7 \%)$ e "Deus" (14,2\%). Cerca de 7\%, apesar de considerarem que o problema tinha solução, não sabiam indicar como proceder para resolvê-lo.

Como pode ser verificado através dos dados anteriores, quando se reportaram aos problemas que mais as incomodavam, a maioria das pessoas referiu aqueles relativos às questões individuais, sendo que a visão de saúde coletiva ou de consciência de grupo foram as menos apontadas. Assim, todos gostariam de ter seus problemas resolvidos, mas aqueles considerados como coletivos eram vistos como responsabilidade de "outros".

Dados apresentados pelo SEADE (1992) evidenciam que, quanto melhores forem as condições de vida, maior será a participação em associações. Explicase que a inserção em diferentes tipos de associações depende das condições de vida da população. Assim, a população com condições de vida mais desfavoráveis relaciona-se mais frequentemente a associações ligadas a questões religiosas, como a igreja, enquanto a população com melhores condições de vida, associa-se mais frequentemente a questões políticas (partidos políticos).

WANDERLEY (1991) afirma em seu estudo "constata-se, ainda, que alguns traços perversos da vida pública nacional, tais como a "lei da vantagem", a corrupção institucionalizada e impune, a violência estrutural e a descrença nos políticos profissionais e nas instituições têm acarretado a apatia, a acomodação, a não participação e o refúgio escapista na vida privada", o que contribuiria para a baixa participação em grupos sociais.

Os dados foram apresentados a uma parcela da população que perfaz o Recanto da Alegria. Na época, sugeriu-se a eles tomar alguns problemas de maior magnitude e discuti-los com a totalidade da população buscando construir em conjunto maneiras de enfrentamento.

Possivelmente, assumindo a colocação de WANDERLEY (1991), essa parcela da população, naquele momento, não manifestou interesse em dar continuidade aos processos de encaminhamento dos problemas. Esse fato revela que possivelmente outras formas de discussão/continuidade tenham que ser apresentadas e/ou construídas com a população que se constituiu em objeto deste estudo.

\section{CONCLUSÃO}

É nesse sentido que este estudo foi realizado, na tentativa de, uma vez aproximando-se às condições de vida e de saúde, identificar problemas que afetariam aquela população e, a partir dessa identificação, propor em conjunto com os grupos acometidos, possibilidades de encaminhamento.

O seu desenvolvimento mostrou, principalmente, a necessidade de se aproximar aos problemas que a coletividade apresenta de forma tal que esta participe ativamente do processo. De outra forma, o profissional pode estar reproduzindo a prática tradicional de apreensão/ resolução de questões de maneira isolada e/ou parcial, o que não garante a aderência às reais necessidades e nem mesmo o impacto positivo no sentido de alteração da realidade existente.

A evidenciação da situação do país em termos de desigualdades sociais determina a necessidade do enfermeiro cumprir seu papel social. Pois, conforme QUEIROZ \& SALUM (1996), "na prática intervir em saúde hoje significa assumir a responsabilidade pelo monitoramento/acompanhamento das condições de saúde da totalidade de população (...) toda intervenção em saúde é intervenção em saúde coletiva (...) intervir no coletivo implica em reconhecer a sua heterogeneidade e superar os limites da assistência individual ou à família ...".

Desta maneira, estaria o enfermeiro pronto a realmente efetivar ações no sentido de diminuir as iniqüidades sociais, uma vez que se torna imperioso o desenvolvimento de metodologias que possam explicitar as desigualdades em saúde, de forma a permitir intervenções diferenciadas sobre os grupos populacionais em função de suas especificidades epidemiológicas, expressas por características econômicas e sociais que lhes são próprias.

\section{LIFE AND HEALTH REALITY AT "RECANTO DA ALEGRIA" COMMUNITY: UNDERSTANDING AND DEFINING THE STRATEGIES OF INTERVENTION}


in order to propose changing strategies to the situation. It took place in Distrito do Grajaú (SP) - Brazil. All families were interviewed through the application of a survey in order to find personal/life conditions, and a health disease process profile. Data reveal a determined profile that was presented to the people to implement integrated actions to solve the main problems/ issues at the community.

\section{APROXIMACIÓN A LA REALIDAD DE VIDA Y DE SALUD DE UNA COMUNIDAD "RECANTO DE LA ALEGRIA": DE SU APREHENSIÓN A LA DEFINICIÓN DE ESTRATÉGIAS DE INTERVENCIÓN}

Este trabajo presenta un proyecto de proceso desarrollado con la finalidad de identificar las condiciones de vida y de salud de una comunidad, para proponer estratégias de transformación a la calidad de vida de su población. El estudio se realizó en una localidad de São Paulo: el distrito de Grajaú. Fue entrevistada la totalidad de las famílias con el objetivo de componer un perfil en términos de sus características personales, de sus condiciones de vida y las relativas al proceso saludenfermedad. Los datos encontrados revelan el perfil que fue presentado a la comunidad en el sentido de ejecutar alternativas conjuntas para la solución de los principales problemas/cuestiones identificados por la población.

TÉRMINOS CLAVES: diagnóstico de salud, enfermería en salud colectiva

\section{REFERÊNCIAS BIBLIOGRÁFICAS}

01. BRANT, V. C.(coord.) São Paulo: trabalhar e viver.São Paulo: Brasiliense, 1989.

02. COSTA, N. do R. Infra estrutura urbana, saneamento e qualidade de vida: notas sobre política pública e desigualdade no Brasil. Saúde Debate, n.29, p.52-6, 1990.

03. DADOS-a. Mulher brasileira: estatísticas de saúde. Rio de Janeiro, v. 10, out. 1986.

04. DADOS-b. Vacinação: pisando em solo fértil. Rio de Janeiro, v. 13, out. 1989.

05. DUCHIADE, M. P. População brasileira: um retrato em movimento. In: MINAYO, M. C. S. (org.) Os muitos Brasis: saúde e população na década de 80. São Paulo/Rio de Janeiro: HUCITEC/ ABRASCO, 1995. p.14-56.

06. FUNDAÇÃO INSTITUTO BRASILEIRO DE GEOGRAFIA E ESTATÍSTICA. FIBGE. Anuário Estatístico Do Brasil: 1992. Rio de Janeiro: SPOC/FIBGE, 1992. v.52.

$07 . \quad$ Anuário Estatístico Do Brasil: 1993. Rio de Janeiro: SPOC/FIBGE, 1993. v.53.

$08 . \quad$ Anuário Estatístico Do Brasil: 1994. Rio de Janeiro: SPOC/FIBGE, 1994. v.54.

09. FUNDAÇÃO SISTEMA ESTADUAL DA ANÁliSE DE DADOS (SEADE). Anuário Estatístico do Estado de São Paulo. São Paulo: Fundação Sistema Estadual de Análise de Dados, 1994. p.71.

10. KON, A. Perfil ocupacional dos assalariados paulistas. São Paulo Perspect., v.8, n.4, p.101-8, 1994.
11. KOWARICK, L.; CAMPOS, A. M. G.; MELLO, M. C. F. Novas formas de pobreza e espaços urbanos em São Paulo: a dimensão perversa da segregação sócio-espacial.In: CONGRESSO BRASILEIRO DE EPIDEMIOLOGIA, 1, Campinas, 1990 Anais. Campinas: Associação Brasileira de Pós-graduação em Saúde Coletiva, 1990.

12. LAURELL, A. C. A saúde como processo social. In: NUNES, E. D. Medicina social: aspectos históricos e teóricos. São Paulo: Global, 1983. p.133-58.

13. LAURENTI, R. Transição demográfica e transição epidemiológica. In: CONGRESSO BRASILEIRO DE EPIDEMIOLOGIA, 1, Campinas, 1990. Anais. Campinas: Associação Brasileira de Pós-graduação em Saúde Coletiva, 1990. p.143-65.

14. MARQUES, M.C.; OLIVEIRA, M.A. de C.; NICHIATA, L.Y.I. Caracterização da região de Capela do Socorro: base para um projeto de intervenção em enfermagem. /Apresentado ao $45^{\circ}$ Congresso Brasileiro de Enfermagem, Recife, $1993 /$.

15. MERCADO informal cresceu $10 \%$ no país, segundo IBGE. Folha de S. Paulo, São Paulo, 21 mar./ 1996. p.4.

16. ORTIZ, L. P. Evolução da mortalidade infantil no Estado de São Paulo segundo sexo, idade, e causas de morte. Informe Demográfico, n.8, 1982. 
17. PAVIANI, A. A lógica da periferização em áreas metropolitanas. In: TERRITÓRIO: globalização e fragmentação. São Paulo: HUCITEC, 1994. p.186-89.

PRATA, P. R. Desenvolvimento econômico, desigualdade e saúde. Cad.Saúde Pública, Rio de Janeiro, v. 10, n. 3, p.387-91, 1994.

18. QUEIROZ, V.M.; SALUM, M.J.L. Reconstruindo a intervenção de enfermagem em saúde coletiva face à vigilância à saúde. São Paulo, 1996 (mimeografado).
19. SEMECHINI, V. C.; ARAUJO, M. F. de. Municípios paulistas: crescimento recente e trajetórias alternativas. São Paulo Perspect., v.3, n.3, p.758. 1989.

20. TROYANO, A. A. et.al. Pesquisa de condições de vida na região metropolitana de São Paulo. São Paulo Perspect., v.5, n.2, p.96-102, 1991.

21. WANDERLEY, L. E. W. Participação popular: poder local e conselhos. São Paulo Perspect., v.5, n.2, p.23-30. 1991.

22. WORLD HEALTH ORGANIZATION. World Health Stat.Q., Geneve, v.48, n.3-4, 1995. 